\title{
Fatigue Crack Growth Behavior for Maglev Switch Beam
}

\author{
[Hesheng Tang, Guiquan Yang, Jiahe Mei]
}

\begin{abstract}
The fatigue crack growth (FCG) behavior of switch beam of the high speed maglev train was systematically investigated using finite element method (FEM) in this paper. Firstly, the stress hot spot of the maglev switch beam was abstained under the train running load (in-plane load) and displacement load during switch (out-of-plane load). Secondly, the stress intensity factors of the hot spot were analyzed under both in-plane and out-of-plane loads. Finally, the FCG rates and the paths for various initial crack positions and types were obtained via the FRANC 3D and ABAQUS based on the maximum circumferential stress criterion including the influence of fatigue life were derived.
\end{abstract}

Keywords-Maglev switch beam, Stress intensity factor, Fatigue crack growth, Fatigue life

\section{Introduction}

As the tool for maglev train runs in line crossing the line, maglev switch beam is an important infrastructure in maglev transportation system [1]. Shanghai maglev train runs with its bogie surrounded by rail, which means maglev rail structure has significant differences with traditional railway [2]. It is essentially a large, with a complex cross section, elastic-flexible welding steel continuous beam.

For welding steel structure, The fatigue strength of welded components is mainly influenced by the following four factors [3]: inevitable weld defects, the stress concentration caused by structure, the welding residual stress and the change of material properties in the heat affected zone (HAZ). Compared with other factors, the stress concentration has the greatest influence on the fatigue strength of components [4].At present, numerical methods for structure crack growth mainly include conventional finite element method [5], meshless method [6], extended finite element method [7], virtual crack closure-integral method [8], boundary element method (BEM) [9]. BEM reduces the number of nodes and the work load greatly because of reducing the dimension of the problem. is widely used. The crack propagation criterion mainly includes the maximum energy release rate criterion [10], the maximum circumferential stress criterion [11], and the minimum strain energy density factor criterion [12]. By investigating 142 steel bridges in Canada and the United States, Fisher and Yuceoglu [13] considered initial defects is the main cause of bridge cracks. There are foreign research institutions have done a lot of structural fatigue test [14-17] to study the fatigue test fracture specimens. The fatigue experiment of the normal stress welded members by Zhou et al. [18] also showed that the fatigue crack basically retained the semielliptical shape during the expansion process. Xiao et al. [1]

\section{Hesheng Tang}

State Key Laboratory for Disaster Reduction in Civil Engineering, Tongji University

Shanghai, China studied the fatigue life of switch beam in four different train conditions. But they all did not consider the influence of different initial crack condition on the fatigue crack growth of switch beam results.

This paper is based on the maximum circumferential stress criterion, combined with the Paris fatigue crack growth model. Inevitable weld defects, the stress concentration caused by structure and the welding residual stress are considered, and the change of the material properties in the HAZ was neglected. Taking the Shanghai Maglev switch beam as an example, the fatigue crack growth behavior is simulated by numerical method, the effects of different initial conditions on crack growth path and fatigue crack life in switch beam structure are studied. The results can not only provide guidance for the relevant test, but also have important theoretical reference and engineering practical value for the fatigue design of switch beam of high speed maglev train.

\section{Numerical Simulation of Crack Growth}

Under the condition of linear elastic fracture mechanics, the fatigue crack growth is assumed to satisfy the Paris model at all points.

$$
\frac{d a}{d N}=C(\Delta K)^{m}
$$

Where, $\Delta \mathrm{K}$ is the stress intensity factor range, $\Delta \mathrm{K}=\mathrm{K}_{\max }$ $-\mathrm{K}_{\min }, \mathrm{m}$ is the material constants.

It is assumed that the complex fatigue crack growth is based on the maximum circumferential stress criterion. In III complex crack, the polar coordinate expression of the stress field near the crack tip is:

$$
\left.\begin{array}{rl}
\sigma_{r}= & \frac{\cos \frac{\theta}{2}}{2 \sqrt{2 \pi r}} K_{\mathrm{I}}(3-\cos \theta)+\frac{\sin \frac{\theta}{2}}{2 \sqrt{2 \pi r}} K_{\mathrm{II}}(3 \cos \theta-1) \\
\sigma_{\theta}= & \frac{\cos \frac{\theta}{2}}{2 \sqrt{2 \pi r}}\left[K_{\mathrm{I}}(1+\cos \theta)-3 K_{\mathrm{II}} \sin \theta\right] \\
\tau_{\theta}= & \frac{\cos \frac{\theta}{2}}{2 \sqrt{2 \pi r}}\left[K_{\mathrm{I}} \sin \theta+K_{\mathrm{II}}(3 \cos \theta-1)\right]
\end{array}\right\}
$$

Where, $r$ is the radial coordinate and $\theta$ is the angular coordinate.

The two basic assumptions of the maximum circumferential stress criterion are: 
- Cracks crack in the direction of maximum circumferential stress $\sigma_{\theta \max }$.

- When the circumferential stress in this direction reaches the critical value, the crack growth is unstable. Which is:

$$
\lim _{r \rightarrow 0} \sqrt{2 \pi r}\left(\sigma_{\theta}\right)_{\max }=K_{I C}
$$

It can be seen from (2) that the extreme values of $\sigma_{\theta}$ cannot be determined because all stress components tend to infinity at $r=0$. So the $\sigma_{\theta}$ can only be compared with each point on the circumference of a tiny distance $r=r_{0}$ from the crack tip, and to solve its extreme value and the corresponding extreme point location, to determine the cracking angle $\theta_{0}$, the crack expansion direction determined by the following equation:

$$
\left\{\begin{array}{l}
\left(\frac{\partial \sigma_{\theta}}{\partial \theta}\right)_{r=r_{0}}=0 \\
\frac{\partial^{2} \sigma_{\theta}}{\partial \theta^{2}}<0
\end{array}\right.
$$

Substituting (4) into (2)

$$
K_{\mathrm{I}} \sin \theta+K_{\mathrm{II}}(3 \cos \theta-1)=0
$$

Assuming that $\theta_{0}$ is the cracking angle that satisfies (5), then the critical stress intensity factor for crack growth $\mathrm{K}_{\mathrm{I}}$ and $\mathrm{K}_{\mathrm{II}}$ is determined:

$$
\cos \frac{\theta_{0}}{2}\left(K_{\mathrm{I}} \cos ^{2} \frac{\theta_{0}}{2}-\frac{3}{2} K_{\mathrm{II}} \sin \theta_{0}\right)=K_{\mathrm{IC}}
$$

Equation (4) and (5) are the basic equations of the maximum circumferential normal stress criterion. It can be seen that the direction of the shear stress $\tau_{\theta}=0$ in the polar coordinates and the circumferential normal stress $\sigma_{\theta}$ are the maximum, the stress intensity factor $\mathrm{K}_{\mathrm{III}}$ has no effect on the cracking angle and the critical load.

The cracking angle can finally be expressed as:

$$
\theta_{0}=2 \tan ^{-1}\left[\frac{1}{4} \frac{K_{\mathrm{I}}}{K_{\mathrm{II}}} \pm \frac{1}{4} \sqrt{\left(\frac{K_{\mathrm{I}}}{K_{\mathrm{II}}}\right)^{2}+8}\right]
$$

\section{Finite Element Modeling and Static Analysis of Critical Nodes of Switch Beam}

\section{A. Maglev Switch Beam Structure}

During the actual operation, the maglev switch beam is subjected to the load of the maglev vehicle and the displace ${ }^{-}$

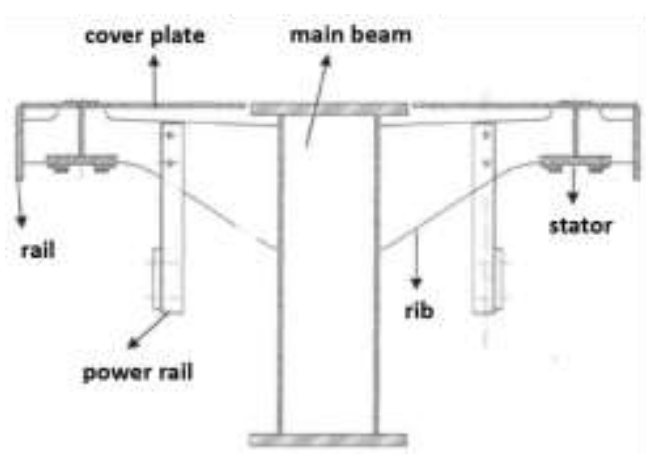

Figure 1. Shanghai Maglev switch beam cross-section

ment load caused by the switch beam during the switch. The maglev switch beam in Shanghai mainly composed of the main beam, ribs, rails, power rail, stator parts and the cover plate, the cross-section is shown in Fig. 1 The main beam section is a box section, the upper flange and the two sides of the web are connected by the ribs, ribs and web are connected by welding, every $0.812 \mathrm{~m}$ set up a transverse diaphragm and ribs.

\section{B. Finite Element Modeling of Critical Nodes of Switch Beam}

From the structure and force characteristics of the maglev switch beam, it can be known that the ribs will cause relatively high stress of the welded joints in the root of the ribbed plate during the traveling load of the maglev train and the lateral movement of the switch beam. The measured results in the reference [1] show that the welded joint between the rib and the web is the fatigue danger point of switch beam, which is the critical node of switch beam.

In order to study the fatigue crack growth behavior of critical nodes in the presence of initial imperfections, ABAQUS software is used to establish the local finite element model of the critical nodes of the magnetic switch beam in this paper, as shown in Fig. 2 The thickness of each component in the model is $20 \mathrm{~mm}$. The geometry of the welding seam is $\mathrm{h}_{f 1}=8 \mathrm{~mm}, \mathrm{~h}_{f 2}=12 \mathrm{~mm}$, as shown in Fig.3, the unit type is mainly a C3D8R solid element. In order to simulate the stress concentration at the weld toe, the C3D20R solid element is adopted in the weld heat affected zone. Material parameters according to the reference [19], the bridge structural steel is $14 \mathrm{MnNbq}$, elastic modulus $\mathrm{E}=$ $210 \mathrm{GPa}$, yield strength $\sigma_{\mathrm{s}}=390 \mathrm{MPa}$.

The following simplifications were made during the modeling process:

- In the beam length direction, take the cross section of rib located as the center to each side to cut $0.2 \mathrm{~m}$ length as the basic calculation length of the model.

- Considering the geometrical symmetry of the cross section and the symmetry of the force of the switch beam, and the research purpose is the fatigue crack growth behavior of the critical node, in this paper, the center of the midline of the cross section is taken as the center of symmetry, and the semi-structure is simulated and analyzed, and the constraint of the fixed end is adopted on the symmetry plane. 


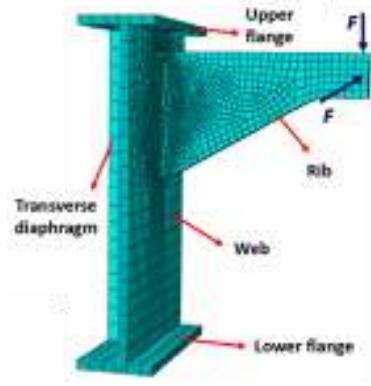

Figure 2. Finite element model of critical node

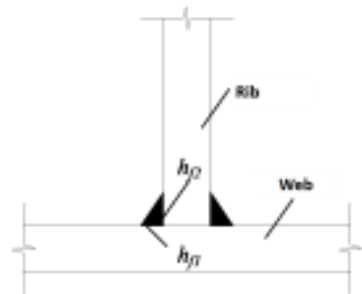

Figure 3. Weld diagram

In the model, the geometric modeling of the functional parts on the flange is simplified, and the concentrated force is applied to simulate the train running load on the vertical rib surface, and the horizontal displacement load is applied outside the cantilever face to simulate the switch beam displacement loads during switch.

\section{Analysis of Critical Node of Switch Beam}

In the end of the cantilever beam applied to the different sizes of concentrated load and displacement load outside the plane. When the in-plane concentrated load is $20 \mathrm{kN}$ and the out-of-plane displacement load is $5 \mathrm{~mm}$, the calculated stress magnitude is close to that of the reference [7]. The stress distribution diagram is shown in Fig.4 and Fig.5 respectively

It can be seen from Fig.4 that when the cantilever end of the ribs is subjected to the in-plane concentrated load, the stress at the upper toe of the ribbed root is the largest at 141.4MPa.Due to the asymmetry of the ribbed plate geometry, the stress at the toe of the lower end of the ribbed plate is smaller than that at the upper end and the size is 100MPa.As shown in Fig.5, when the cantilever end of the rib is subjected to out-of-plane displacement load, the maximum stress is also at the toe of the top of the ribbed plate, and the size is $172.9 \mathrm{MPa}$.Similarly, due to the geometric dimensions of the ribbed plate, the stress at the toe of the lower end of the ribbed plate is smaller than the upper end stress, and the size is $66.2 \mathrm{MPa}$.According to the above analysis, the root of the toe of the rib root is the stress hot spot of the critical node, which is the dangerous part of fatigue.

\section{Iv. Analysis of Crack Growth at Hot Spot}

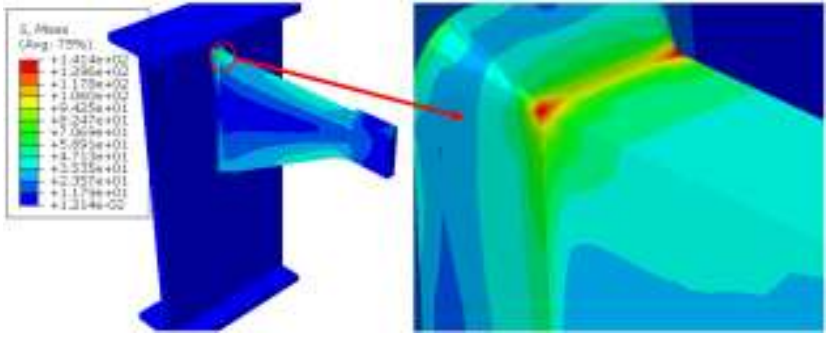

Figure 4. Stress distribution diagram under concentrated load in the plane

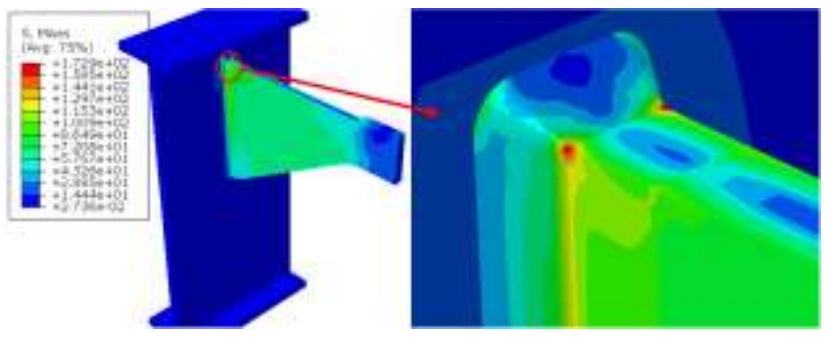

Figure 5. Stress distribution diagram under displacement load outside the plane

\section{A. Simulation of Crack Growth Path}

The initial crack is introduced into the hot spot. The initial crack size short axis $\mathrm{a}_{0}=1 \mathrm{~mm}$ and the major axis radius $\mathrm{c}_{0}=2 \mathrm{~mm}$, and the crack growth is analyzed under both in-plane and out-of-plane loads. Among them, in the plane is $20 \mathrm{kN}$ concentrated load, stress ratio $\mathrm{R}=0$, stress amplitude is 141.4MPa; Outside the plane is $5 \mathrm{~mm}$ displacement load, stress ratio $\mathrm{R}=0$, the normal stress amplitude is $172.9 \mathrm{MPa}$. (Herein, the in-plane load and the out-of-plane load, stress ratio, and stress amplitude are the same as those herein, unless otherwise specified).Including the simulation of crack growth trajectory, the analysis of stress intensity factor during crack growth, the prediction of crack growth life and the analysis of crack shape.

When the surface crack length in the direction of plate thickness reaches the plate thickness under in-plane load, the analysis is stopped. Under the action of out-of-plane loading, when the surface crack length in the thickness direction reaches $60 \%$ of the plate thickness, the analysis is stopped. A total of 20-step crack growth analysis using FRANC3D and ABAQUS was carried out. Fig.6(a) shows the variation of the crack shape as the crack propagates progressively under the action of in-plane $20 \mathrm{kN}$ load. It can be seen from the figure that the crack extends from the quarter-elliptic initial corner of the hot spot to the interior of the weld, and the spreading speed in the thickness direction of the rib is larger than that in the plane of the rib. Fig.6(b) shows the fatigue crack growth process under the action of out-of-plane $5 \mathrm{~mm}$ displacement load. It can be seen from the figure that the initial crack propagates to the interior of the weld in the plane of the rib and the crack trajectory on the surface of the weld is basically a straight line. The initial crack propagates in the thickness direction of the ribs toward the direction away from the toe. The growth path is an arc segment, and the spreading velocity in the thickness direction of the rib is less than that in the plane of the rib. 


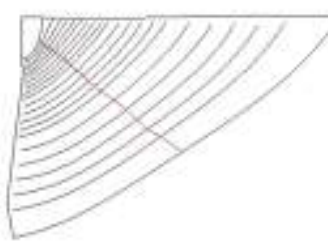

(a) In-plane load

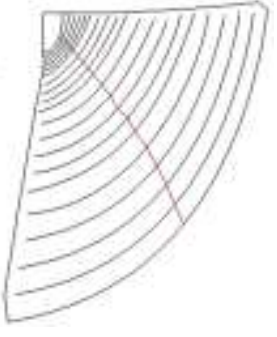

(b) Out-of-plane load
Figure 6. Fatigue crack growth

\section{B. Analysis of Stress Intensity Factor of Crack}

According to the stress intensity factor theory, the stress intensity factor determines the stress state near the crack tip, and the crack growth size and crack growth direction is also closely related to the stress intensity factor. The crack growth size is determined by the magnitude of the relative stress intensity factor at each point and the crack growth size at the midpoint of the stress intensity factor. In order to better describe the distribution of stress intensity factors and the law of crack growth, we choose the three points A, B and $\mathrm{C}$ in Fig.7 as the reference points.

Fig. 8 shows the distribution of the I-type stress intensity factor along the crack front after the initial crack and the crack tip extending through steps 5, 10, 15 and 20.It can be seen from Fig.8(a) that the distribution of the stress intensity factor $K_{\mathrm{I}}$ along the crack front is approximately the same for each extension step crack under $20 \mathrm{kN}$ concentrated load in the plane. In addition to the small fluctuation at point $\mathrm{A}$ and point $\mathrm{B}$, the value of stress intensity factor $K_{\mathrm{I}}$ of crack front I-type increases with the crack growth. And the expansion speed at the point B increases relatively faster than the point $\mathrm{A}$ and the point C. From Fig.8(b), it can be seen that the distributions of crack initiation stress intensity factor $K_{\mathrm{I}}$ along the crack front are significantly different under the 5 $\mathrm{mm}$ displacement load. At point $\mathrm{A}$, the value of $K_{\mathrm{I}}$ increases slightly with the crack growth, and the value of $K_{\mathrm{I}}$ at point $\mathrm{C}$ increases significantly from the initial crack growth to the fifth step, and then decreases with the crack growth. At point B, the value of $K_{\mathrm{I}}$ decreases drastically with the crack growth. It can be deduced that at point $\mathrm{A}$, the crack growth rate will increase slowly, and the crack growth rate will decrease slowly at point $\mathrm{C}$, and the crack growth speed will decrease at point $\mathrm{B}$. This is consistent with the results obtained in the simulation of the crack growth trajectory above.

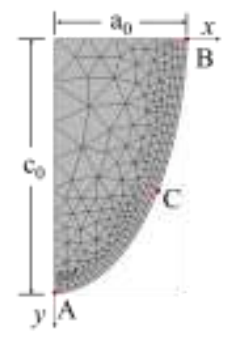

Figure 7. Initial crack shape

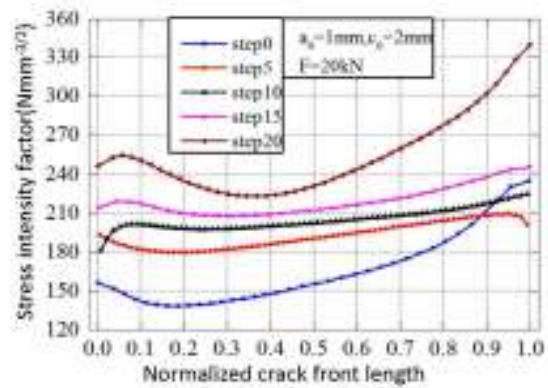

(a) In-plane load

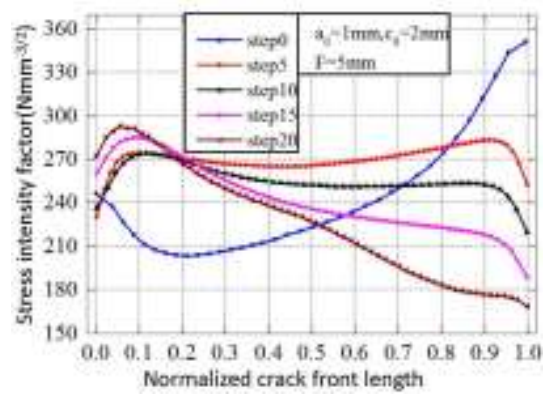

(b) Out-of-plane load

Figure 8. $K_{\mathrm{I}}$ distribution during crack growth

Based on the maximum normal stress criterion, the crack growth direction will be directly determined by the ratio of the II-type stress intensity factor $\mathrm{K}_{\mathrm{II}}$ and the I-type stress intensity factor $\mathrm{K}_{\mathrm{I}}$. Therefore, the stress intensity factor of the three types of cracks at the point $\mathrm{C}$ of the crack front is shown in Fig.9 as a function of crack growth. It

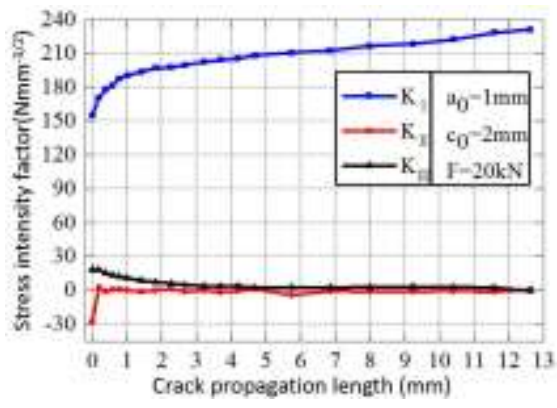

(a) In-plane load

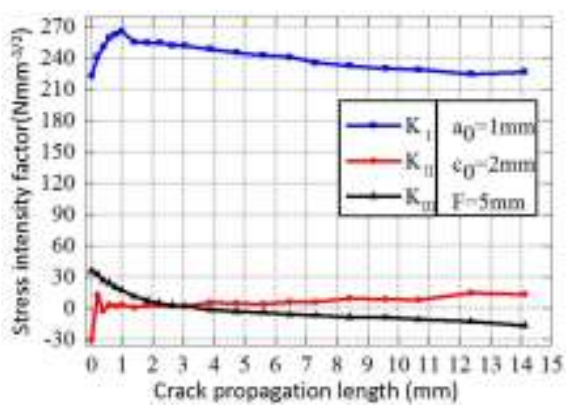

(b) Out-of-plane load

Figure 9. Stress intensity factor change curve during crack growth 
can be seen from the figure that the crack types are complex cracks with I type mainly in the whole process of crack growth under the two loads of in-plane and out-plane. However, it can be seen from Fig.9(a) that the values of $K_{\text {II }}$ and $K_{\text {III }}$ gradually approach to zero with the expansion of the crack, indicating that the crack type gradually changes from compound type to type I crack. However, in Fig.9(b), $K_{\text {II }}$ slowly increases after experiencing fluctuations of the first few extension steps, while $K_{\text {III }}$ decreases slowly throughout the whole spreading process. However, $K_{\mathrm{II}}$ and $K_{\mathrm{III}}$ values are smaller than $K_{\mathrm{I}}$ in the whole process, so the crack type is still the compound type crack mainly with I type.

\section{v. Analysis of Crack Growth}

\section{A. Analysis of Crack Growth Shape}

Suppose the initial crack size $\mathrm{a}_{0}=1 \mathrm{~mm}, \mathrm{c}_{0}=2 \mathrm{~mm}$. During crack growth, the ratio of the crack length in the thickness direction (point B) and the crack length in the plane of the rib plate (at point $\mathrm{A}$ ) is a/c. Under different initial conditions $\mathrm{a}_{0} / \mathrm{c}_{0}$, the process of change is shown in Fig.10. It can be seen from Fig.10(a) and (b) that as the crack propagates, the ratio of a/c will no longer be constant, but will continue to change as the crack growth. The change rule is that under the same load, the a/c of different initial conditions will tend to be a fixed value with the crack growth. The results show that the initial crack shape has little effect on the final crack shape

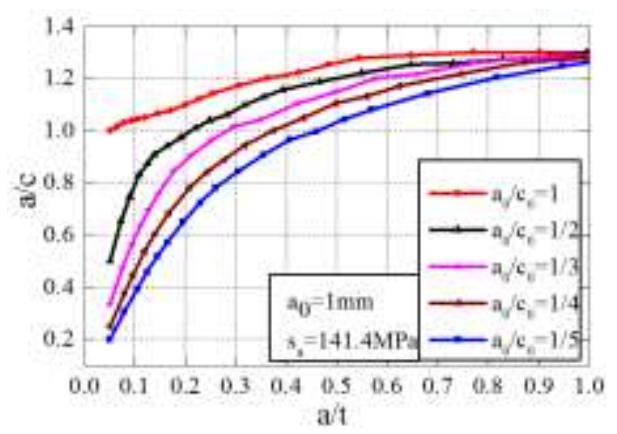

(a) In-plane load

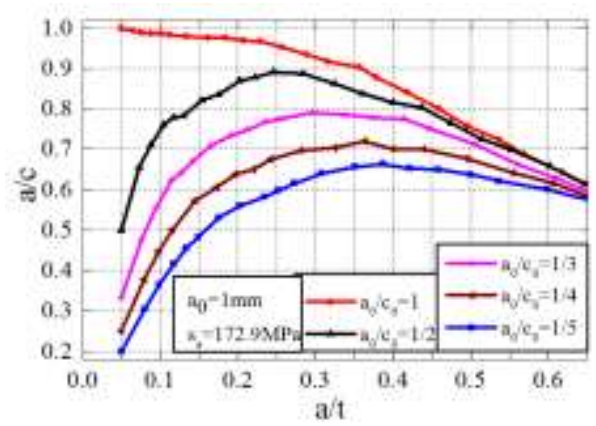

(b) Out-of-plane load

Figure 10. a/c change in crack growth under different initial conditions

\section{B. Analysis of Initial Crack Location}

Consider the initial crack analysis model at three different locations as shown in Fig.11, and perform fatigue crack growth analysis.

Fig.12 shows the relationship between the fatigue crack growth length and the number of load cycles at point B at the crack tip at different locations of the initial crack. It can be seen from Fig.12(a) that the crack growth velocity decreases drastically as the crack position moves away from the hot spot along the weld toe, and the fatigue crack life increases significantly under the in-plane concentrated load. From Fig.12(b), it can be found that the fatigue crack life of Crack1 is much larger than that of Crack2 and Crack3, and the fatigue crack lives of Crack 2 and Crack3 are similar. Therefore, the initial defect of the weld at the hot spot will be far greater than the initial defect of other regions. Particular attention should be given to the presence of initial weld defects at the hot spots and the initiation of initial cracks at the hot spots during use.

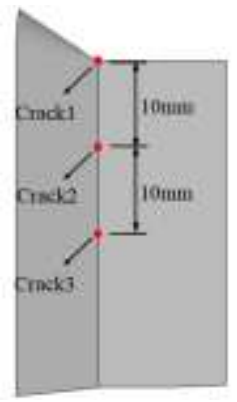

Figure 11. Different locations of the initial crack

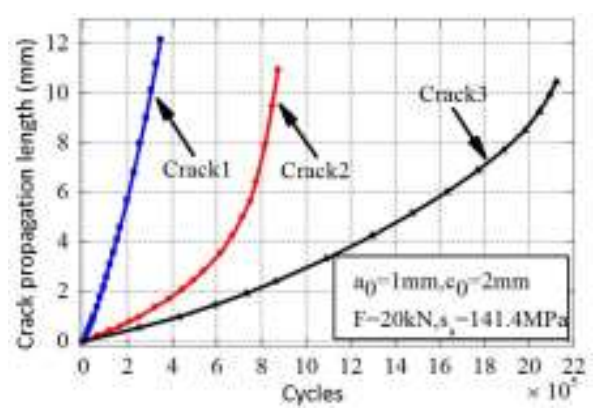

(a) In-plane load

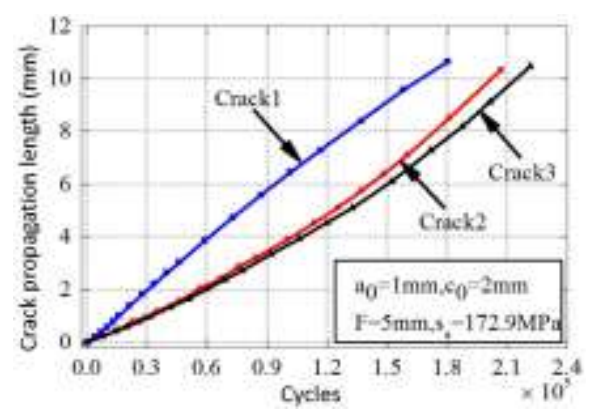

(b) Out-of-plane load

Figure 12. Fatigue crack life at different initial crack locations 


\section{Analysis of Load Size}

The fatigue crack life at the hot spots in the in - plane loads are $20 \mathrm{kN}, 30 \mathrm{kN}$ and $40 \mathrm{kN}$, the stress ratio is 0 , the stress amplitudes are $141.4 \mathrm{MPa}, 212.1 \mathrm{MPa}$ and $282.8 \mathrm{MPa}$; the out-of-plane loads are $3 \mathrm{~mm}, 5 \mathrm{~mm}$ and $7 \mathrm{~mm}$, the stress ratio is 0 , the stress amplitudes are $103.7 \mathrm{MPa}, 172.9 \mathrm{MPa}$, 242.1MPa six cases is calculated respectively.

Fig.13 shows the relationship between the crack length and the number of load cycles at different loads at the point B. It can be seen from the figure that the fatigue crack life at the hot spot is very sensitive to the change of the load size under both in-plane and out-of-plane loads. With the increase of load, the number of load cycles decreases sharply, and the fatigue crack life is shortened.

\section{Analysis of Initial Crack Size}

The fatigue crack growth at the initial crack radius of $0.5 \mathrm{~mm}, 1 \mathrm{~mm}, 3 \mathrm{~mm}$ and $5 \mathrm{~mm}$ is calculated respectively under the two loads of in-plane and out-of-plane.

Fig.14 shows the relationship between the crack length and the number of load cycles at different initial crack sizes at the B-point of the crack front. From Fig.14(a), as the initial crack size increases, the crack growth velocity gradually increases. When the crack propagates the same length, the number of load cycles decreases gradually. Under the action of out-of-plane load, due to the stress intensity factor at point $\mathrm{B}$ is similar at the different initial crack radius, and the stress intensity factor at point B decreases gradually, the crack growth velocity gradually decline, as the crack propagates the same length,

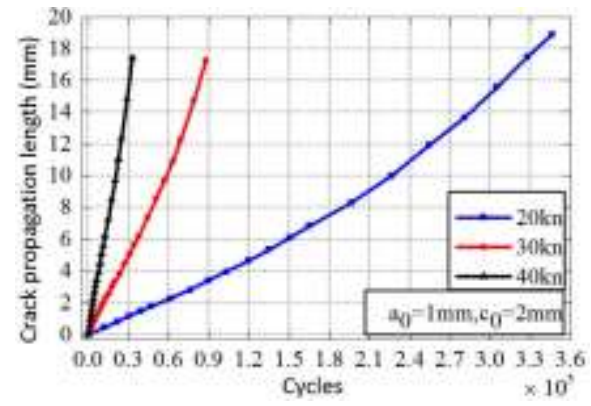

(a) In-plane load

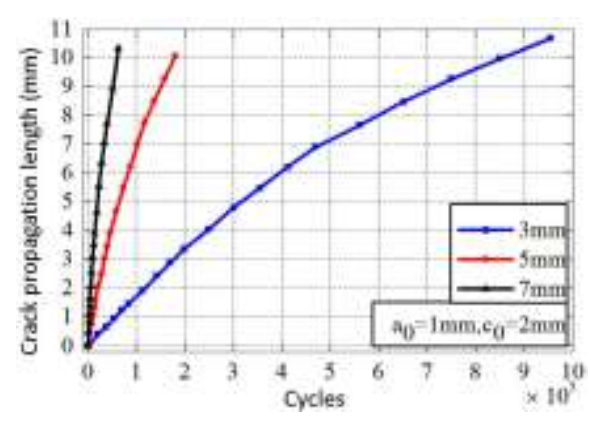

(b) Out-of-plane load

Figure 13. Fatigue crack life under different loads

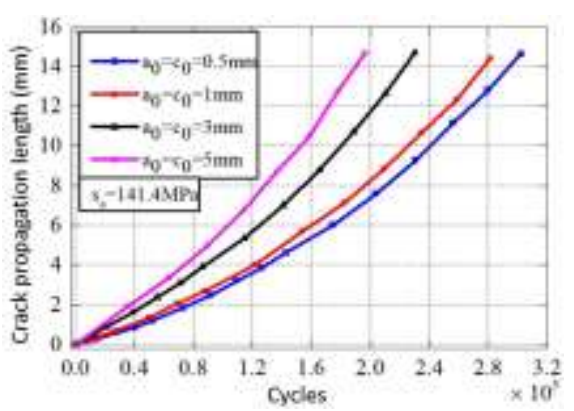

(a) In-plane load

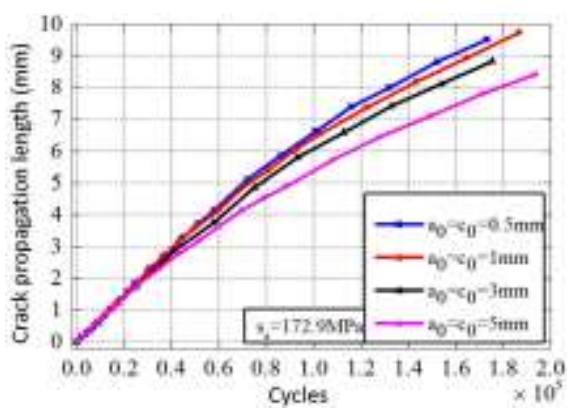

(b) Out-of-plane load

Figure 14. Fatigue crack life under different initial crack sizes

the number of load cycles increases gradually with the initial crack, as shown in Fig.14(b).

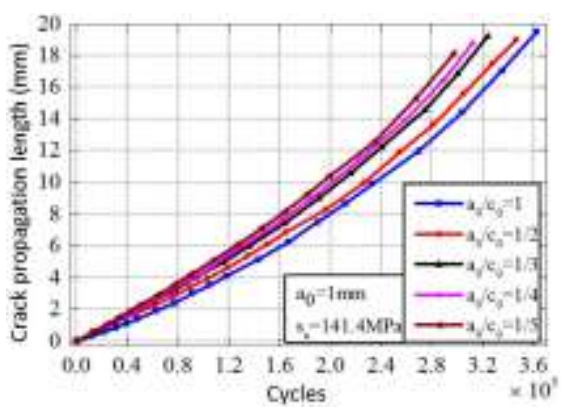

(a) In-plane load

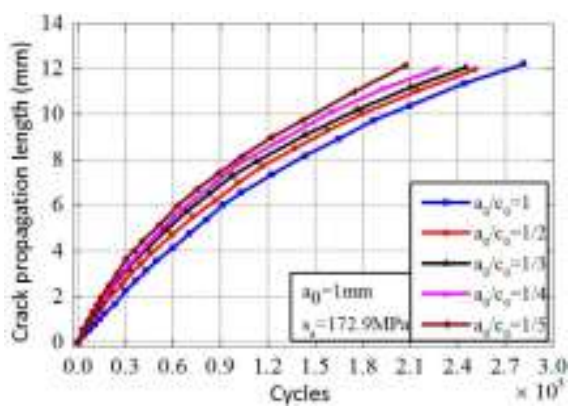

(b) Out-of-plane load

Figure 15. Fatigue crack life under different initial crack shapes 


\section{E. Analysis of Initial Crack Shape}

The fatigue crack life at the hot spots of $c_{0}=1 \mathrm{~mm}, 2 \mathrm{~mm}$, $3 \mathrm{~mm}, 4 \mathrm{~mm}$ and $5 \mathrm{~mm}$ under the In-plane and out-of-plane load, respectively, is calculated by taking $\mathrm{a} 0=1 \mathrm{~mm}$, while keeping the initial crack in the thickness direction of the ribs.

Fig. 15 shows the relationship between the crack length and the number of load cycles at point $\mathrm{B}$ at different initial crack shapes. From the figure, with the increase of $\mathrm{c} 0$, the fatigue crack growth rate increases slowly. When the crack propagates the same length, the number of load cycles decreases gradually.

\section{vI. Conclusion}

In this paper, the stress hot spot is firstly determined by the static analysis of the critical node of the switch beam. Then, based on the maximum circumferential stress criterion and the Paris fatigue crack growth model, the fatigue crack growth is simulated with FRANC3D. Then, by means of the comparative method, the effects of different initial conditions such as initial crack location, loading size, initial crack size, and initial crack shape on crack growth path, fatigue crack life and crack growth shape were studied. The main conclusions are as follows:

- Under the action of the in-plane load, the initial angle crack at the hot spot gradually spreads to the inside of the weld. Under the action of out-of-plane load, the initial angle crack ribs are extended to the interior of the weld, but the thickness direction of the rib is gradually extended away from the weld.

- In the process of crack growth, the values of stress intensity factors of type II and III are very small compared with the values of type I stress intensity factor in the front of the crack, the crack type is compound crack with I-type crack as the main component.

- Under the action of in-plane and out-of-plane loads, at different initial conditions $\mathrm{a}_{0} / \mathrm{c}_{0}$, the ratio of the crack length at point $\mathrm{B}$ to the crack length at point $\mathrm{A}$ $(\mathrm{a} / \mathrm{c})$ is gradually approaching, indicating that regardless of the initial crack shape, the final crack shape will gradually close with the crack growth.

- Under the action of in-plane and out-of-plane loads, among the factors influencing the fatigue crack life, the initial crack location and the load size are the most obvious. As the initial crack location gradually farther away from the hot spot and the load decreases, fatigue crack life will be significantly increased. But the initial crack size, including the size and shape of the initial crack on the fatigue crack life of the impact is relatively small.

\section{Acknowledgment}

This study was supported by the Ministry of Science and Technology of China, Grant No. SLDRCE14-B-03 and the National Natural Science Foundation of China, Grant No. $51578140,51178337$.

\section{References}

[1] Z. Xiao, "Study on dynamic stress and fatigue life of maglev switch beam," Southwest Jiaotong University, 2011, pp. 64-75.

[2] X. Wu, Maglev train. Shanghai: Shanghai Science and Technology Press, 2003.

[3] C. Chen, Fatigue and fracture. Wuhan: Huazhong University of Science and Technology Press, 2002.

[4] L. Huo, Fracture Behavior and Assessment of Welded Structures. Beijing: China Mechanical Press, 2000.

[5] R. A. Smith and J. F. Cooper, "A finite element model for the shape development of irregular planar cracks," International journal of pressure vessels and piping, 4th ed., vol. 36, pp. 315-326, 1989.

[6] T. Belytschko, Y. Y. Lu, L. Gu, "Element-free galerkin methods," International journal for numerical methods in engineering, 2nd ed., vol. 37, pp. 229-256, 1994.

[7] J. Chessa, T. Belytschko. "A local space-time discontinuous finite element method," Computer Methods in Applied Mechanics and Engineering, 13th ed., vol. 195, pp. 1325-1343, 2006.

[8] X. Fang, F. Jin, J. Wang, "Cohesive model based on extended finite element method," Journal of Tsinghua University: Natural Science Edition, 3rd ed., vol. 47, pp. 344-347, 2007.

[9] D. Yang, Z. Zhao, Boundary element theory and application. Beijing: Beijing Institute of Technology Press, 2002.

[10] K. Palaniswamy, W. G. Knauss, "On the problem of crack extension in brittle solids u nder general loading," Mechanics today, 4th ed., vol. 30, pp. 87-148, 1978.

[11] F. Erdogan, G. C. Sih, "On the crack extension in plates under plane loading and transverse shear," Journal of basic engineering, 4th ed., vol. 85, pp. 519-525, 1963.

[12] G. C. Sih, "Some basic problems in fracture mechanics and new concepts," Engineering fracture mechanics. 2nd ed., vol. 5, pp. 365377,1973

[13] J. W. Fisher, U. Yueeoglu. A Survey of Localized Cracking In Steel Bridges. Washington DC, 1981.

[14] CM. Suh, MS. Suh, NS. Hwang, "Growth behaviour of small surface fatigue cracks in AISI 304 stainless steel," Fatigue and Fracture of Engineering Materials and Structures, 1th ed., vol. 35, pp. 22-29, 2012.

[15] AMG. Figueiredo, GDO. Ribeiro, JF. Dias, et al., "An investigation of bending fatigue crack propagation in structural steel by the measurement of indirect parameters", Journal of the Brazilian Society of Mechanical Sciences and Engineering, 1st ed., vol. 37, pp. 305312, 2015.

[16] R. Ebara, "Fatigue crack initiation and propagation behavior of forging die steels," International Journal of Fatigue, 5th ed., vol. 32, pp. 830-840, 2010.

[17] M. Maruyama, N. Akutsu, K. Aoyama, et al., "Ductile crack initiation and propagation in steel bridge piers subjected to random cyclic loading," Engineering Structures, 2nd ed., vol. 59, pp. 809-820, 2014.

[18] T. Zhou, "Local thermal stress analysis of bridge members and its fatigue damage accumulation process simulation," Southeast University, 2003, pp. 68-88.

[19] Y. Liu, C. Chen, J. Li, et al., "Fatigue crack growth behavior for the weld heat-affected zone of $14 \mathrm{MnNbq}$ bridge steel," Engineering Mechanics, 4th ed., vol. 25, pp. 209-213, 2008. 